\title{
Function of prostaglandin $E_{2} E P$ receptors in the acute outcome of rodent hypoxic ischemic encephalopathy
}

\author{
Hidetoshi Taniguchi ${ }^{1,{ }^{* \star}}$, Christoph Anacker ${ }^{1,2}$, Gabriela Beatriz Suarez-Mier $^{1}$, Qian Wang ${ }^{1}$, \\ and Katrin Andreasson ${ }^{1}$ \\ ${ }^{1}$ Department of Neurology and Neurological Sciences, Stanford University School of Medicine, \\ Stanford, CA 94305
}

\section{Abstract}

Neonatal hypoxic-ischemic encephalopathy (HIE) is a leading cause of severe and permanent neurologic disability after birth. The inducible cyclooxygenase COX-2, which along with COX-1 catalyzes the first committed step in prostaglandin (PG) synthesis, elicits significant brain injury in models of cerebral ischemia, however its downstream PG receptor pathways trigger both toxic and paradoxically protective effects. Here, we investigated the function of $\mathrm{PGE}_{2}$ E-prostanoid (EP) receptors in the acute outcome of hypoxic-ischemic (HI) injury in the neonatal rat. We determined the temporal and cellular expression patterns of the EP1-4 receptors before and after HIE and tested whether modulation of EP1-4 receptor function could protect against cerebral injury acutely after HIE. All four EP receptors were expressed in forebrain neurons and were induced in endothelial cells after HIE. Inhibition of EP1 signaling with the selective antagonist SC-51089 or co-activation of EP2-4 receptors with the agonist misoprostol significantly reduced HIE cerebral injury $24 \mathrm{~h}$ after injury. These receptor ligands also protected brain endothelial cells subjected to oxygen glucose deprivation, suggesting that activation of EP receptor signaling is directly cytoprotective. These data indicate that the G-protein coupled EP receptors may be amenable to pharmacologic targeting in the acute setting of neonatal HIE.

\section{Keywords}

$\mathrm{PGE}_{2}$; EP1-4 receptors; G-protein coupled receptors; misoprostol; hypoxic ischemic encephalopathy

\section{INTRODUCTION}

Hypoxic ischemic encephalopathy (HIE) in the neonate is one of the leading causes of cerebral palsy, mental retardation, and learning disabilities, making it critical to identify therapeutic strategies to reduce brain injury in HIE. The inducible cyclooxygenase COX-2 has been implicated in cerebral injury in models of adult stroke [8], and is induced in HIE where it is associated with acute hypoxic ischemic events [18].

\footnotetext{
(C) 2011 Elsevier Ireland Ltd. All rights reserved.

${ }^{* *}$ Correspondence should be addressed to: Stanford University School of Medicine 1201 Welch Road MSLS P250 Stanford, CA 94305 hide-tan@ped.med.osaka-u.ac.jp .

${ }^{2}$ Present address: Department of Psychological Medicine [C.A.], Institute of Psychiatry, King's College London, London SE5 9NU, U.K

Publisher's Disclaimer: This is a PDF file of an unedited manuscript that has been accepted for publication. As a service to our customers we are providing this early version of the manuscript. The manuscript will undergo copyediting, typesetting, and review of the resulting proof before it is published in its final citable form. Please note that during the production process errors may be discovered which could affect the content, and all legal disclaimers that apply to the journal pertain.
} 
The cyclooxygenases COX-1 and COX-2 catalyze the first committed step in the formation of prostaglandins from arachidonic acid. COX-2 is rapidly upregulated in neurons following $\mathrm{N}$-methyl-D-aspartate (NMDA) receptor-dependent synaptic activity [26], consistent with a physiologic role in modulating synaptic plasticity. COX-2 expression and activity are also induced in neurons in vivo in acute paradigms of excitotoxicity, and promote ischemic injury (reviewed in [8]). In models of neurodegeneration, where inflammation is a dominant pathological component, COX-2 is upregulated in microglia, where it is promotes secondary neuronal injury [8]. The mechanism by which COX-2 activity promotes neurotoxicity is due to actions of one or more downstream prostaglandin (PG) signaling pathways through specific $\mathrm{PG}$ receptors. The five downstream prostanoid products of COX activity, $\mathrm{PGE}_{2}$, $\mathrm{PGF}_{2 \mathrm{a}}, \mathrm{PGD}_{2}, \mathrm{PGI}_{2}$ (prostacyclin), and $\mathrm{T} \times \mathrm{A}_{2}$ (thromboxane $\mathrm{A}_{2}$ ) bind to specific $\mathrm{G}$ proteincoupled receptors designated EP (for E-prostanoid), FP, DP, IP, and TP receptors, respectively [5]. PG receptor subtypes are distinguished by which $\mathrm{PG}$ they bind, and by the signal transduction pathway that is activated upon ligand binding. Activation of PG receptors leads to changes in the production of cAMP and/or phosphoinositol turnover and intracellular $\mathrm{Ca}^{2+}$ mobilization. Further complexity occurs in the case of $\mathrm{PGE}_{2}$, which can bind four receptor subtypes (EP1, EP2, EP3, and EP4) with distinct and potentially antagonistic signaling cascades.

$\mathrm{PGE}_{2}$ is a major downstream product of COX-2 enzymatic activity and a potent lipid messenger that activates four distinct G-protein coupled receptors, the EP1-EP4 receptors. In experimental stroke, levels of COX-2 and $\mathrm{PGE}_{2}$ are markedly upregulated [15] and COX-2 can exert neurotoxicity via the $\mathrm{Ga}_{\mathrm{q}}$-coupled $\mathrm{EP} 1$ receptor in vivo $[2,9,27]$. However, neuronal PG receptors that are positively coupled to cAMP can elicit paradoxical protective effects in vitro in excitotoxic and hypoxic paradigms [4,12,14], indicating that both protective as well as toxic PG signaling pathways may be active in cerebral ischemia $[3,13$, 14]. In this study, we examined the function of the $\mathrm{PGE}_{2} \mathrm{EP}$ receptors in acute outcome in a rodent model of HIE using pharmacologic strategies. We identified cerebroprotective effects of misoprostol, an agonist to the EP2-4 receptors as well as the EP1 antagonist SC-51089.

\section{MATERIALS AND METHODS}

\section{Animals and surgical procedures}

All animal experiments were approved by Administrative Panel on Laboratory Animal Care (APLAC) at Stanford University. The rodent model of neonatal rat HIE was carried out according to the protocol established by Rice et. al. and as previously described [17, 21]. Sham treated animals underwent ligation of the carotid artery but no hypoxia. Vehicle, SC-51089 $(10 \mu \mathrm{g} / \mathrm{kg})$, misoprostol $(50 \mu \mathrm{g} / \mathrm{kg}$ or $500 \mu \mathrm{g} / \mathrm{kg})$ were administered intraperitoneally either $5 \mathrm{~min}$ before or $5 \mathrm{~min}$ after hypoxia. Twenty-four hours after HI, Sprague Dawley rat pups were lethally anesthetized and brain tissue was harvested for infarct quantification using 1\% 2,3,5-triphenyl-tetrazolium chloride (TTC) staining in a blinded fashion [21].

\section{Immunocytochemistry}

Rat pups ( $\mathrm{n}=2-3$ per time point) were deeply anesthetized with isoflurane and transcardially perfused with normal saline followed by $4 \%$ PFA, then overnight fixation in PFA at $4^{\circ} \mathrm{C}$. Brains were processed for paraffin sections ( $5 \mu \mathrm{m}$ thickness). Infarct area was determined with cresyl violet staining. Following antigen retrieval (in citrate $\mathrm{pH}$ 6.0, boiled in a microwave for $20 \mathrm{~min}$ ) and permeabilization with $0.3 \%$ triton together with blocking with $10 \%$ normal goat serum for $1 \mathrm{~h}$, immunostaining for EP1-4 was carried out using anti-EP1-4 polyclonal antibodies (1/500; Cayman Chemical, Ann Arbor, MN) overnight at $4^{\circ} \mathrm{C}$ followed by secondary antibody (biotinylated anti rabbit IgG, VECTOR, Burlingame, CA) 
and detection reagents (DAB: $3^{\prime}, 3^{\prime}$-diaminobenzidine tetrahydrochloride, Polysciences Inc, Warrington, PA). Images were acquired with a Leica DM5000B microscope and a Leica DC500 camera and digitized using software PictureFrame 2.3 (Optronics, Goleta, CA). Double immunofluorescence was performed using EP1-4 polyclonal antibodies (Cayman Chemical, Ann Arbor, MI) and anti-Factor VIII mouse monoclonal antibody (Invitrogen) followed by Alexa fluor® 488 anti-mouse and Alexa fluor ${ }^{\circledR} 546$ anti-rabbit antibody. Images were acquired with a Nikon E400 with an Orca ER CCD camera and digitized using Open Lab and Volocity software (Improvision).

\section{Oxygen-glucose deprivation of primary neuronal and bEND3 cell cultures}

Primary hippocampal neuronal cultures were subjected to oxygen-glucose deprivation (OGD; $3 \mathrm{~h}$ ) as previously described $[11,14]$. The immortalized mouse brain endothelial bEND3 cell line was subjected to $6 \mathrm{~h}$ of OGD. Cell death in neuronal cultures was quantified by cell counting of propidium iodine (PI)/Hoechst labeled nuclei as previously described [14]. bEND3 cell death was similarly determined by PI fluorescence quantification in 96-well plates, using a fluorescence spectrophotometric assay of PI fluorescence levels (Spectra Max M5, Molecular Devices, Sunnyvale, CA); the levels of PI fluorescence in OGD conditions was compared to a standard curve consisting of a range of cells/well that had been frozen $-80^{\circ} \mathrm{C}$ overnight to obtain complete cell death and subsequently stained with PI. Caspase 3 activity in neurons was measured using the Caspase 3/7 Glo ${ }^{\circledR}$ assay (Promega, Madison, WI) using a luminometer (Spectra Max M5, Molecular Devices, Sunnyvale, CA).

\section{Statistical Analysis}

Statistical analysis was performed by Student's $t$-test or one-way and two-way analysis of variance (ANOVA), followed by Tukey post hoc analysis. All data are reported as mean \pm standard error of the mean (SEM). $p$ values $<0.05$ were considered significant.

\section{RESULTS}

\section{EP1-4 receptors are expressed in neurons and endothelial cells in the rodent HIE brain}

Spatiotemporal expression patterns of EP1-4 receptors were examined in sham pups and pups subjected to HI. Expression of EP1-4 was examined in frontal cerebral cortex (layer II/ III) in the penumbral region (Figure 1A) at $3 \mathrm{~h}$ and 24h after HIE. Expression of EP1-4 receptors was examined in cerebral microvasculature at $24 \mathrm{~h}$ at the rostral border of infarcted tissue, as determined with cresyl violet stain. Immunostaining for EP1-4 demonstrated that all $4 \mathrm{EP}$ receptors were expressed in cortical neurons, as well as in striatal and hippocampal pyramidal neurons (data not shown). At $3 \mathrm{~h}$ after HIE, EP1, 2, and 4 receptor expression was increased in the ipsilateral ischemic hemisphere in both neurons and endothelium (Figure 1). At 24h after HI, neuronal EP3 signal was markedly decreased whereas EP1, EP2, and EP4 expression levels persisted. Colocalization studies using Factor VIII as a marker of endothelial cells demonstrated that EP1-4 receptors were expressed by endothelial cells $24 \mathrm{~h}$ after HI (Figure 2).

\section{Inhibition of EP1 receptor activity protects against HIE}

The EP1 receptor is unique among the four EP receptors in that it is coupled to Gaq, and activation of EP1 receptor results in increased phosphatidyl inositol hydrolysis and elevation of the intracellular $\mathrm{Ca}^{2+}$ concentration. Previous studies in adult models of transient focal ischemia indicate that EP1 activation mediates the toxic effect of COX-2 [9]. Here we tested whether similar mechanisms would be active in the perinatal brain. The selective EP1 antagonist SC-51089 $(10 \mu \mathrm{g} / \mathrm{kg})$ was administered after 100 minutes of HI and infarct 
volumes were measured $24 \mathrm{~h}$ later (Figure 3). Inhibition of EP1 signaling elicited significant protection and reduced infarct volume by $28.5 \%(\mathrm{p}<0.01 ; \mathrm{n}=9-11$ per group $)$. A parallel experiment testing the effect of EP1 antagonist $(10 \mu \mathrm{g} / \mathrm{kg})$ administered before HI did not demonstrate any effect $(35.4 \%, \pm 4.5$ for vehicle vs $43.6 \% \pm 6.3$ for SC51089). As shown in Figures 1 and 2, immunostaining of brain tissue in control and $\mathrm{HI}$ brains demonstrate expression of EP1 both in endothelium and neurons in ipsilateral infarcted cortex. We tested EP1 effects on neuronal and endothelial cell viability in a paradigm of OGD that models the hypoxic insult in vivo [14], and measured nuclear PI fluorescence as an index of cell death. Inhibition of EP1 activation using a dose response of SC-51089 rescued bEND mouse endothelial cell death caused by $6 \mathrm{~h}$ of OGD (ANOVA $\mathrm{p}<0.001$ ) as well as primary hippocampal neurons subjected to $3 \mathrm{~h}$ of OGD (ANOVA $\mathrm{p}<0.01$; Figure $3 \mathrm{E}$ and F). In neurons subjected to OGD, inhibition of EP1 activity reduced levels of caspase-3 activity (ANOVA p <0.01; Figure 3G) in a dose-dependent manner. Thus, in vitro OGD cell viability assays indicate that EP1 receptor activity functions in both endothelial and neuronal cell death.

\section{The EP2-4 receptor agonist misoprostol protects against $\mathrm{HI}$ in neonatal rat brain}

Misoprostol is a widely used anti-ulcer agent in patients who are at risk for non-steroidal anti-inflammatory drug (NSAID)-mediated gastritis and ulcer disease and repletes cytoprotective levels of $\mathrm{PGE}_{2}$ necessary for maintaining integrity of the gastric mucosa. Misoprostol binds the EP2, EP3 and EP4 receptors and increases cAMP production, indicating activation of the EP2 and EP4 receptors $[6,7,16,24]$. We have previously demonstrated that administration of misoprostol exerted significant cerebroprotection in a model of adult transient focal ischemia [11], and we tested whether misoprostol may also be effective in acute outcome of postnatal HIE (Figure 4). Administration of misoprostol before but not after $\mathrm{HI}$ reduced infarct volume in a dose-dependent manner (ANOVA $\mathrm{p}<0.05$ ). Post-hoc analysis further showed a more significant rescue of male HIE (ANOVA $\mathrm{p}<0.0001$ ) than female HIE (NS).

We have previously demonstrated that individual activation of the EP2, EP3, or EP4 receptors on neurons was protective in settings of excitotoxicity and/or OGD [4, 11, 14, 25], however administration of misoprostol, which binds EP2, EP3, and EP4 receptors together had no effect on neuronal survival [11]; this suggested that the protective effect of misoprostol administration may not be through neuroprotection in vivo. Because these receptors are expressed in microvasculature, we tested whether misoprostol may have cytoprotective effects in bEND cells subjected to OGD. Administration of misoprostol to bEND3 endothelial cells subjected to 6h of OGD significantly rescued cell death (ANOVA $\mathrm{p}<0.0001$ ), indicating that one potential cerebroprotective mechanism of misoprostol may be via enhancement of endothelial viability (Figure 4F).

\section{DISCUSSION}

In this study, we have investigated the function of the $\mathrm{PGE}_{2} \mathrm{EP} 1-4$ receptors in the acute outcome at $24 \mathrm{~h}$ in a rat model of HIE using a selective pharmacologic antagonist to the EP1 receptor (SC51089) and an agonist to the EP2-4 receptors (misoprostol). Previous studies in adult models of cerebral ischemia have demonstrated protective effects of an EP1 antagonist when given after ischemia [9], and up to $12 \mathrm{~h}$ after vessel occlusion [1], supporting the translational relevance of targeting this receptor after onset of ischemia. Misoprostol, which is well tolerated in patients with gastric ulcers, is significantly protective in a model of adult transient focal ischemia as well [11], and is similarly protective in HIE, however only if administered prior to $\mathrm{HI}$ at the dosing given in this study. 
The EP1 receptor is expressed in neurons in the post-natal rat brain and is induced in vasculature. It is not clear why EP1 antagonism was more effective after hypoxia, however this could be due to different cellular mechanisms that are activated before and after HI. In neurons, neuroprotection may be induced by EP1 effects on $\mathrm{Na}^{+} / \mathrm{Ca}^{2+}$ exchangers [9] and on the PTEN/AKT pathway [27]. In addition to rescue of neuronal death in vitro, EP1 blockade also rescued endothelial cell death in cultured bEND cells subjected to OGD. EP1 inhibition may be acting by enhancing endothelial cell viability, but may also be involved in regulation of cerebral perfusion, as suggested in one study where deletion of the EP1 had beneficial effects on cerebral blood flow and reduced the severity of cerebral ischemia [19]. Taken together, these mechanistic studies suggest that inhibition of EP1 may be cerebroprotective through a multicellular mechanism involving neuronal and endothelial protection and enhanced cerebral perfusion.

Activation of the EP2-4 receptors with misoprostol also exerts cerebroprotection. Examination of gender differences revealed significant protection in males but not females. Our previous studies examining cell injury in organotypic postnatal rat hippocampal slices demonstrated gender differences following excitotoxic and OGD injury, where female slices exhibited reduced injury compared to male slices [10]; indeed, there is substantial evidence that neuronal injury occurs in a gender dimorphic manner, with neurotoxicity mediated by caspase-dependent mechanisms in females but caspase-independent mechanisms in males [20]. However, misoprostol does not appear to be neuroprotective in vitro in neuronal cultures subjected to excitotoxic or hypoxic stimuli [11], suggesting that misoprostol protection may not be targeting the gender-dependent neuronal cell death pathways, but perhaps may be targeting non-neuronal EP receptors. In fact, as EP2-4 are expressed in blood vessels in addition to neurons, misoprostol could potentially exert its effect through vascular EP2-4 on endothelial cell viability. The cytoprotective effects observed in endothelial cells with misoprostol treatment lend support to this hypothesis. The brain permeability of either misoprostol or SC51089 in rodent brain is not clear. It is possible that the protective effects of these EP ligands could be mediated via endothelial mechanisms, however because there is blood brain barrier breakdown in the setting of cerebral ischemia, we hypothesize that these agents could penetrate the parenchyma, and in the case of the EP1 antagonist, could act on neuronal EP1 receptors.

In this study, we did not investigate long-term functional outcome measures of the EP1 antagonist SC51089 and the EP2-4 agonist misoprostol; we would suspect a single dose may not be sufficient to elicit significant functional recovery in stringent measures such as Morris Water Maze, and that multiple dosing over time would likely be required to see a long term effect. Nevertheless, the robust acute cerebroprotection seen with both compounds supports further investigation and testing of repeated administration of these ligands using more comprehensive behavioral testing weeks to months after HI, including the Morris Water maze to test spatial memory, a behavioral paradigm that has been successfully used to assess functional recovery after HIE [23].

The EP1 antagonist SC51089 and the EP2-4 agonist misoprostol exerted cytoprotective effects in brain endothelial cells subjected to OGD. In previous findings, the DP1 receptor, a $\mathrm{PG}$ receptor for $\mathrm{PGD}_{2}$ that is also positively coupled to cAMP production, also mediated endothelial cell protection in HI [22]. These findings suggest that PG signaling, particularly via PG receptors that are positively coupled to cAMP, may function in enhancing endothelial viability in the setting of ischemia. Given the fact that EP receptors are G-protein coupled receptors that are accessible to therapeutic targeting particularly on endothelial cells, this study offers initial support to further investigations into the actions of these receptors in HIE. 


\section{Acknowledgments}

This work was supported by the Tashia and John Morgridge Child Health Research Institute Fellowship at Stanford University (HT), the American Heart Association (HT), March of Dimes (KA), NIH R01NS045727 (KA), AHA (KA), Weston Havens Foundation (KA), International Max Planck Research School (CA), and the German Academic Foundation (CA). The authors thank Gary Steinberg, David Kunis, and Marion Buckwalter for their generous assistance.

\section{ABBREVIATIONS}

$\begin{array}{ll}\text { COX } & \text { cyclooxygenase } \\ \text { EP } & \text { E-prostanoid } \\ \text { HI } & \text { hypoxia-ischemia } \\ \text { HIE } & \text { hypoxic ischemic encephalopathy } \\ \text { NSAID } & \text { non-steroidal anti-inflammatory drug } \\ \text { OGD } & \text { oxygen-glucose deprivation } \\ \text { PFA } & \text { paraformaldehyde } \\ \text { PG } & \text { prostaglandin } \\ \text { PI } & \text { propidium iodine } \\ \text { TTC } & \text { 2,3,5-triphenyl-tetrazolium chloride }\end{array}$

\section{REFERENCES}

[1]. Abe T, Kunz A, Shimamura M, Zhou P, Anrather J, Iadecola C. The neuroprotective effect of prostaglandin E2 EP1 receptor inhibition has a wide therapeutic window, is sustained in time and is not sexually dimorphic. J Cereb Blood Flow Metab. 2009; 29:66-72. [PubMed: 18648380]

[2]. Ahmad AS, Saleem S, Ahmad M, Dore S. Prostaglandin EP1 receptor contributes to excitotoxicity and focal ischemic brain damage. Toxicol Sci. 2006; 89:265-270. [PubMed: 16237196]

[3]. Andreasson K. Prostaglandin signalling in cerebral ischaemia. Br J Pharmacol. 2010; 160:844846. [PubMed: 20590583]

[4]. Bilak M, Wu L, Wang Q, Haughey N, Conant K, St Hillaire C, Andreasson K. PGE2 receptors rescue motor neurons in a model of amyotrophic lateral sclerosis. Ann Neurol. 2004; 56:240 248. [PubMed: 15293276]

[5]. Breyer RM, Bagdassarian CK, Myers SA, Breyer MD. Prostanoid receptors: subtypes and signaling. Annu Rev Pharmacol Toxicol. 2001; 41:661-690. [PubMed: 11264472]

[6]. Breyer RM, Davis LS, Nian C, Redha R, Stillman B, Jacobson HR, Breyer MD. Cloning and expression of the rabbit prostaglandin EP4 receptor. Am J Physiol. 1996; 270:F485-493. [PubMed: 8780252]

[7]. Fedyk ER, Ripper JM, Brown DM, Phipps RP. A molecular analysis of PGE receptor (EP) expression on normal and tranformed B lyphocytes: coexpression of EP1, EP2, EP3beta and EP4. Mol. Immunol. 1996; 33:33-45. [PubMed: 8604222]

[8]. Hewett SJ, Bell SC, Hewett JA. Contributions of cyclooxygenase-2 to neuroplasticity and neuropathology of the central nervous system. Pharmacology \& therapeutics. 2006; 112:335357. [PubMed: 16750270]

[9]. Kawano T, Anrather J, Zhou P, Park L, Wang G, Frys KA, Kunz A, Cho S, Orio M, Iadecola C. Prostaglandin E2 EP1 receptors: downstream effectors of COX-2 neurotoxicity. Nat Med. 2006; 12:225-229. [PubMed: 16432513]

[10]. Li H, Pin S, Zeng Z, Wang MM, Andreasson KA, McCullough LD. Sex differences in cell death. Ann Neurol. 2005; 58:317-321. [PubMed: 15988750] 
[11]. Li J, Liang X, Wang Q, Breyer RM, McCullough L, Andreasson K. Misoprostol, an anti-ulcer agent and PGE(2) receptor agonist, protects against cerebral ischemia. Neurosci Lett. 2008; 438:210-215. [PubMed: 18472336]

[12]. Liang X, Wu L, Hand T, Andreasson K. Prostaglandin D2 mediates neuronal protection via the DP1 receptor. J Neurochem. 2005; 92:477-486. [PubMed: 15659218]

[13]. Liu D, Wu L, Breyer R, Mattson MP, Andreasson K. Neuroprotection by the PGE2 EP2 receptor in permanent focal cerebral ischemia. Ann Neurol. 2005; 57:758-761. [PubMed: 15852374]

[14]. McCullough L, Wu L, Haughey N, Liang X, Hand T, Wang Q, Breyer RM, Andreasson K. Neuroprotective function of the PGE2 EP2 receptor in cerebral ischemia. J Neurosci. 2004; 24:257-268. [PubMed: 14715958]

[15]. Nogawa S, Zhang F, Ross ME, Iadecola C. Cyclo-oxygenase-2 gene expression in neurons contributes to ischemic brain damage. J Neurosci. 1997; 17:2746-2755. [PubMed: 9092596]

[16]. Reimer R, Heim HK, Muallem R, Odes HS, Sewing KF. Effects of EP-receptor subtype specific agonists and other prostanoids on adenylate cyclase activity of duodenal epithelial cells. Prostaglandins. 1992; 44:485-493. [PubMed: 1361678]

[17]. Rice JE 3rd, Vannucci RC, Brierley JB. The influence of immaturity on hypoxic-ischemic brain damage in the rat. Ann Neurol. 1981; 9:131-141. [PubMed: 7235629]

[18]. Riezzo I, Neri M, De Stefano F, Fulcheri E, Ventura F, Pomara C, Rabozzi R, Turillazzi E, Fineschi V. The timing of perinatal hypoxia/ischemia events in term neonates: a retrospective autopsy study. HSPs, ORP-150 and COX2 are reliable markers to classify acute, perinatal events. Diagn Pathol. 2010; 5:49. [PubMed: 20626887]

[19]. Saleem S, Li RC, Wei G, Dore S. Effects of EP1 receptor on cerebral blood flow in the middle cerebral artery occlusion model of stroke in mice. J Neurosci Res. 2007; 85:2433-2440. [PubMed: 17600836]

[20]. Siegel C, Turtzo C, McCullough LD. Sex differences in cerebral ischemia: possible molecular mechanisms. J Neurosci Res. 2010; 88:2765-2774. [PubMed: 20698025]

[21]. Taniguchi H, Andreasson K. The hypoxic-ischemic encephalopathy model of perinatal ischemia. J Vis Exp. 2008

[22]. Taniguchi H, Mohri I, Okabe-Arahori H, Aritake K, Wada K, Kanekiyo T, Narumiya S, Nakayama M, Ozono K, Urade Y, Taniike M. Prostaglandin D2 protects neonatal mouse brain from hypoxic ischemic injury. J Neurosci. 2007; 27:4303-4312. [PubMed: 17442814]

[23]. Ten VS, Bradley-Moore M, Gingrich JA, Stark RI, Pinsky DJ. Brain injury and neurofunctional deficit in neonatal mice with hypoxic-ischemic encephalopathy. Behav Brain Res. 2003; 145:209-219. [PubMed: 14529818]

[24]. Ungrin MD, Carriere MC, Denis D, Lamontagne S, Sawyer N, Stocco R, Tremblay N, Metters KM, Abramovitz M. Key structural features of prostaglandin E(2) and prostanoid analogs involved in binding and activation of the human EP(1) prostanoid receptor. Mol Pharmacol. 2001; 59:1446-1456. [PubMed: 11353805]

[25]. Wu L, Wang Q, Liang X, Andreasson K. Divergent effects of prostaglandin receptor signaling on neuronal survival. Neurosci Lett. 2007; 421:253-258. [PubMed: 17574754]

[26]. Yamagata K, Andreasson KI, Kaufmann WE, Barnes CA, Worley PF. Expression of a mitogeninducible cyclooxygenase in brain neurons: regulation by synaptic activity and glucocorticoids. Neuron. 1993; 11:371-386. [PubMed: 8352945]

[27]. Zhou P, Qian L, Chou T, Iadecola C. Neuroprotection by PGE2 receptor EP1 inhibition involves the PTEN/AKT pathway. Neurobiol Dis. 2008; 29:543-551. [PubMed: 18178094] 


\section{Highlights}

- We test the function of the PGE2 receptors in neonatal hypoxia ischemia (HIE)

- All four PGE2 receptors are expressed after neonatal hypoxia ischemia

- Inhibition of the EP1 receptor is cerebroprotective

- Activation of the EP2-4 receptors is cerebroprotective

- Supports future study of these G-protein coupled receptors in HIE 


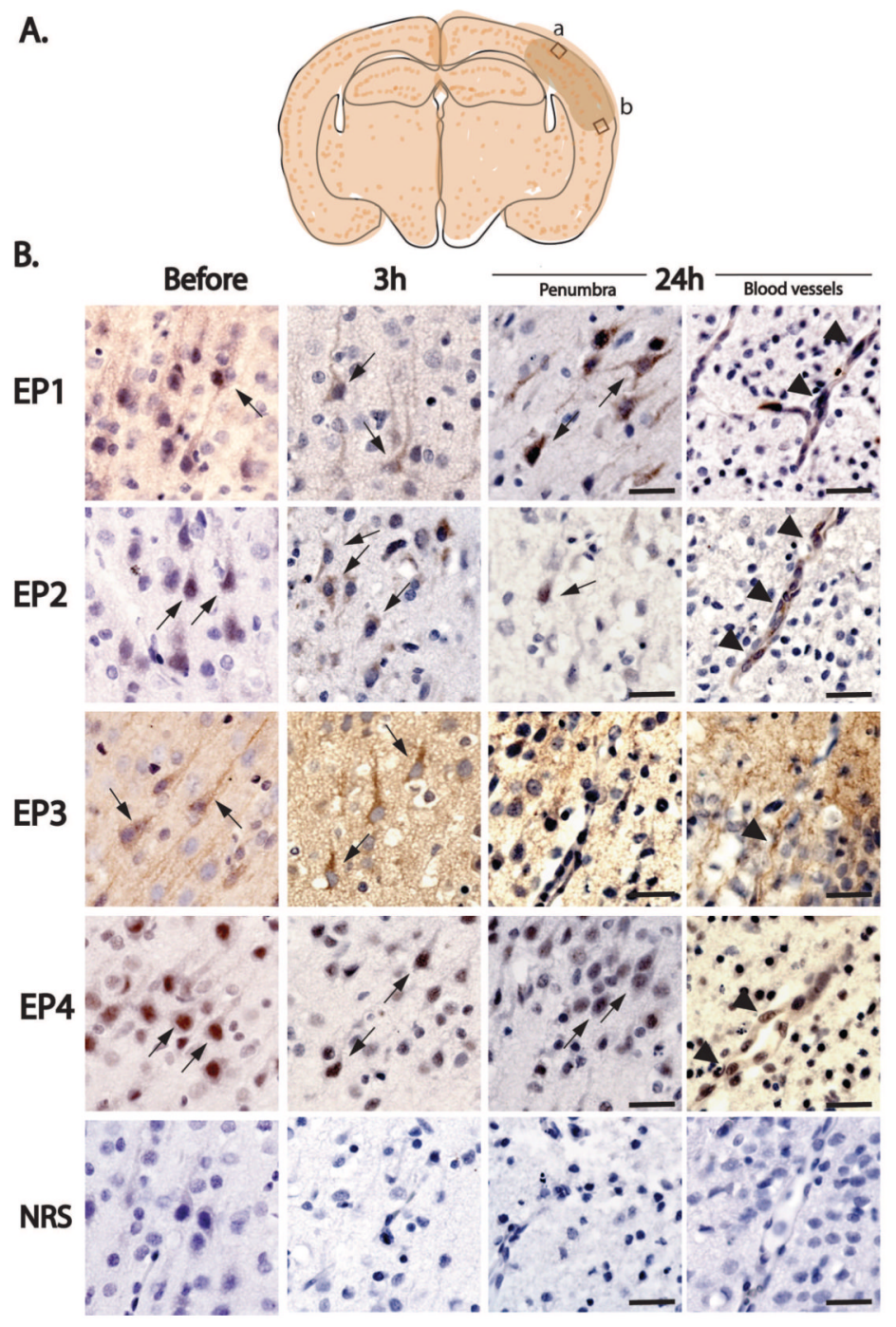

Figure 1. Immunohistochemistry of EP1-4 receptors in postnatal rat HIE brains

(A) Schema of the cortical areas examined (box a: within infarct zone; box b: penumbra). EP1-4 receptor expression was examined in cerebral cortex in layers II/III dorsally and ventrally to the infarct area in the penumbra at $3 \mathrm{~h}$ and $24 \mathrm{~h}$ after HI. (B) EP1-4 receptors are dynamically regulated in sham (just before onset of hypoxia) and HI ( $3 \mathrm{~h}$ and $24 \mathrm{~h}$ after hypoxia) pups in cerebral cortical neurons (thin arrows) and microvasculature (arrowheads). Normal rabbit serum (NRS) control stains did not show specific staining. Scale bar $=50 \mu \mathrm{m}$ 


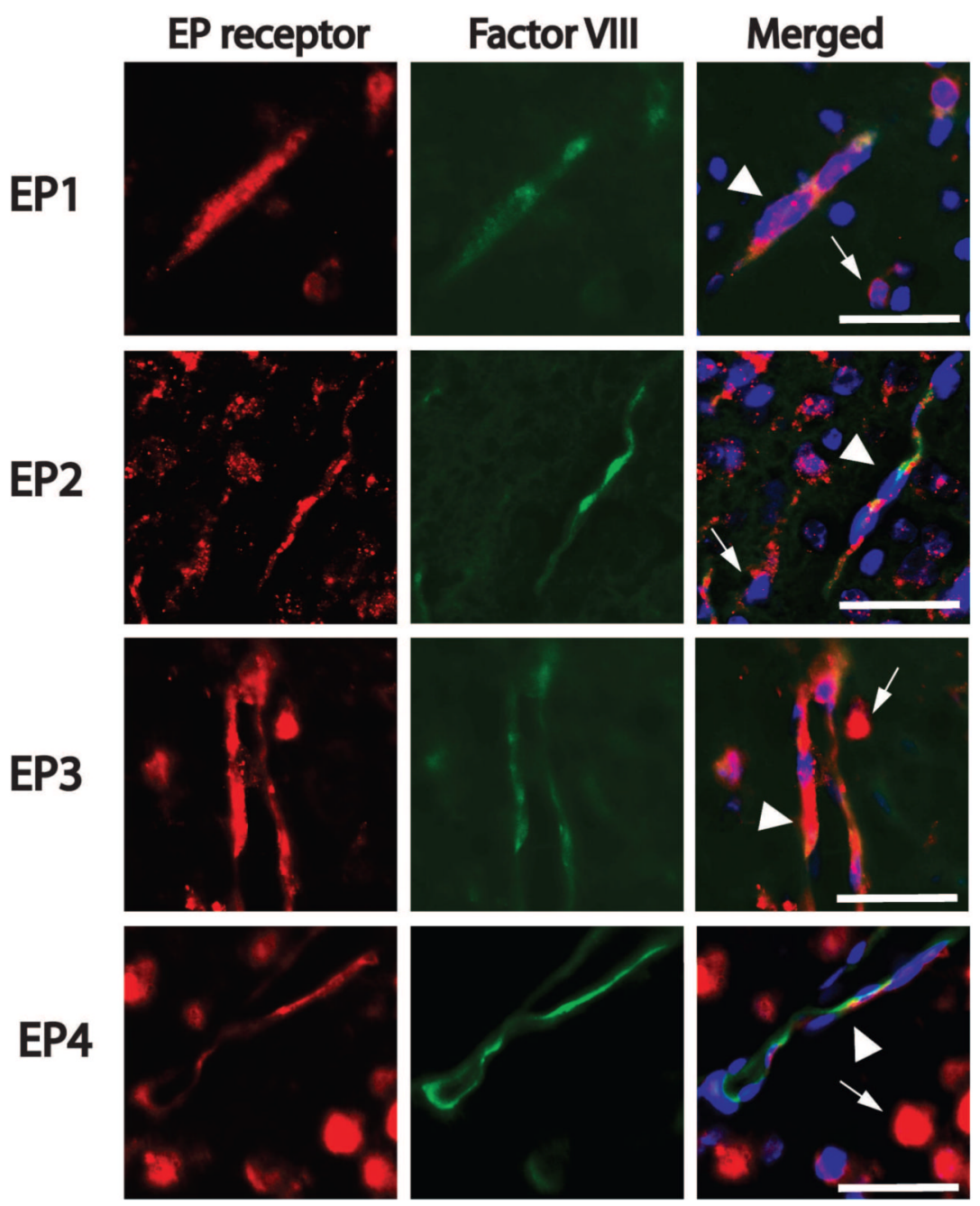

Figure 2. Colocalization of EP1-4 receptors and the endothelial marker Factor VIII in cerebral cortical penumbra at $24 \mathrm{~h}$ after $\mathrm{HI}$

Colocalization of EP receptors and the endothelial marker Factor VIII was examined in cortical layers II/III as shown in Figure 1A. Sections were counter stained with the nuclear stain Hoechst 33258 (blue). EP1-4 receptors colocalize with Factor VIII (arrowheads); in addition, EP receptors were present on non-endothelial cells (thin arrows), likely representing neurons, as shown in Figure 1. Scale bar $=50 \mu \mathrm{m}$. 
A

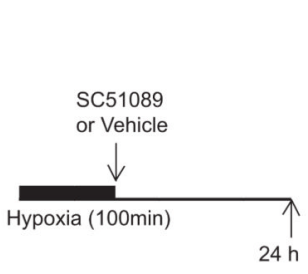

C
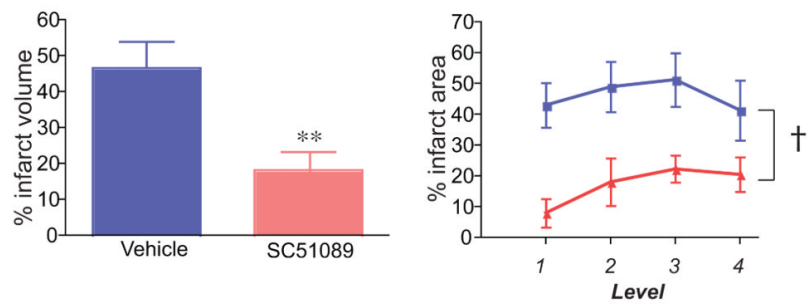

B

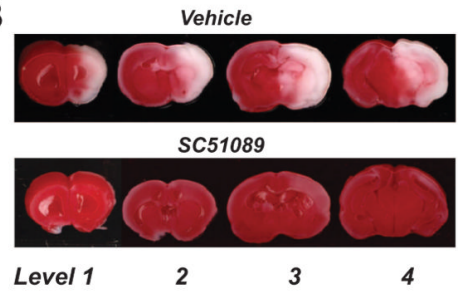

D

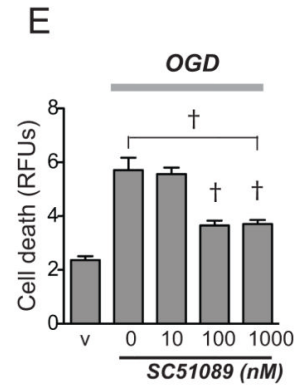

$\mathrm{F}$
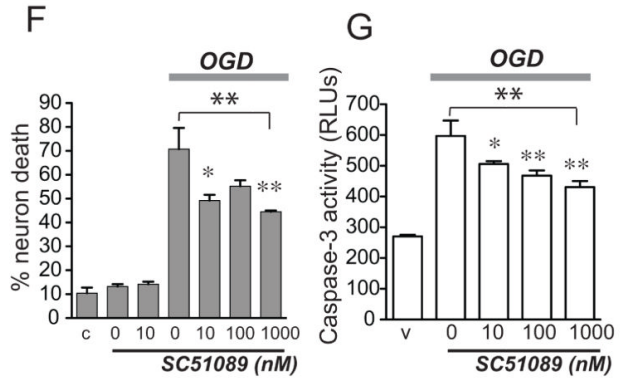

Figure 3. Administration of EP1 antagonist SC51089 significantly protects against HIE injury (A) Diagram of experimental strategy where SC51089 (10 $\mu \mathrm{g} / \mathrm{kg})$ was given after HI. (B) Representative TTC stained coronal sections (levels 1-4) from postnatal day 7 rat brains 24 $\mathrm{h}$ after HI. (C) Quantification of hemispheric infarct volume by TTC demonstrates cerebroprotective effect of SC51089 (**p<0.01; $n=9-11$ per group). (D) Quantification of percent infarct area at each of the four levels demonstrates a significant decrease in infarct area in SC51089-treated group (pink) compared to Vehicle-treated group (blue; 2-way ANOVA, $\dagger \mathrm{p}<0.001 ; \mathrm{n}=9-11$ ). (E) SC51089 reduces bEnd3 cell death induced after $6 \mathrm{~h}$ of OGD (ANOVA $\mathrm{p}<0.001$; post-hoc $\uparrow \mathrm{p}<0.001$ for $100 \mathrm{nM}$ and $1 \mu \mathrm{M}$ SC 51089 ; $\mathrm{n}=6-8$ per condition). (F) SC51089 reduces hippocampal neuronal cell death induced after $3 \mathrm{~h}$ of OGD (ANOVA ** $<<0.01$; post-hoc *p $<0.05$ for $10 \mathrm{nM}$ and $* * \mathrm{p}<0.01$ for $1 \mu \mathrm{M}$ SC51089; $\mathrm{n}=4-6$ per condition). (G) SC51089 reduces caspase-3 activity in hippocampal neurons subjected to $3 \mathrm{~h}$ of OGD (ANOVA **p $<0.01$; post hoc $* \mathrm{p}<0.05$ for $10 \mathrm{nM}$ and $* * \mathrm{p}<0.01$ for $100 \mathrm{nM}$ and $1 \mu \mathrm{M} ; \mathrm{n}=6-8$ per condition; RFU: relative fluorescence unit; RLU: relative light unit) 
A

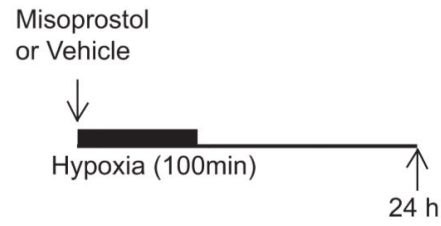

C

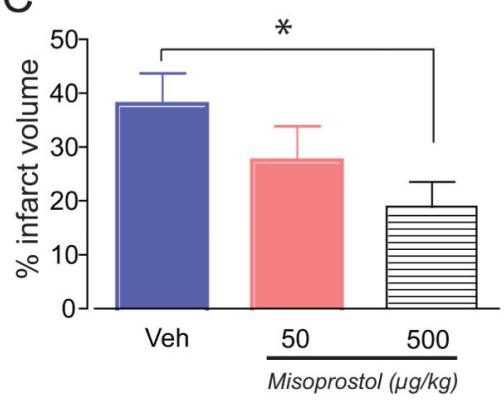

E

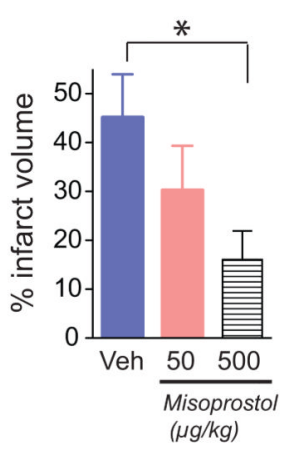

B

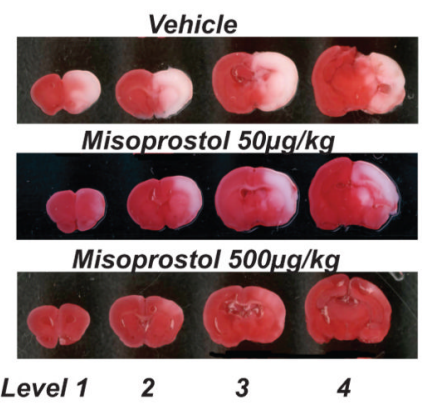

$\mathrm{D}$

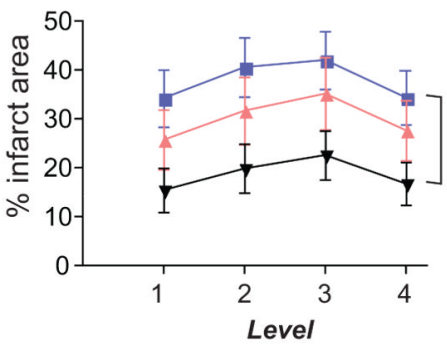

$\mathrm{F}$

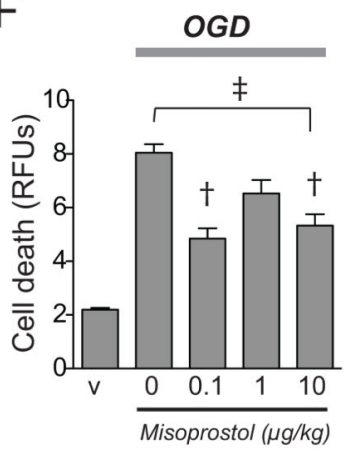

Figure 4. Administration of the EP2-4 agonist misoprostol protects against injury

(A) Time scale of treatment with misoprostol $50 \mu \mathrm{g} / \mathrm{kg}$ or $500 \mu \mathrm{g} / \mathrm{kg}$ before HIE. (B)

Representative series of TTC stained coronal sections 24h after HI. (C) Administration of misoprostol significantly decreases infarct volume at a dose of $500 \mu \mathrm{g} / \mathrm{kg}(* \mathrm{p}<0.05 ; \mathrm{n}=23-25$ per group). (D) Quantification of percent infarct area at each of the four levels demonstrates a significant decrease in infarct area for $500 \mu \mathrm{g} / \mathrm{kg}$ dose (black) but not for $50 \mu \mathrm{g} / \mathrm{kg}$ dose (pink) compared to vehicle (blue; $2 \mathrm{w}$ ANOVA of vehicle and $500 \mu \mathrm{g} / \mathrm{kg} \dagger \mathrm{p}<0.001$ ). (E) Misoprostol exerts gender-dimorphic pattern of cerebroprotection in male, but not female pups (ANOVA male pups, ${ }^{*} \mathrm{p}<0.05 ; \S=\mathrm{NS} ; \mathrm{n}=10-13$ per group). (F) Misoprostol reduces bEND3 endothelial cell death (ANOVA $\ddagger \mathrm{p}<0.0001$; post-hoc $\dagger \mathrm{p}<0.001$ for 0.1 and $10 \mu \mathrm{M}$ ). 